\title{
Persistence at 12 months with denosumab in postmenopausal women with osteoporosis: interim results from a prospective observational study
}

\author{
S. L. Silverman • E. Siris • D. L. Kendler • D. Belazi • J. P. Brown • D. T. Gold • \\ E. M. Lewiecki - A. Papaioannou - C. Simonelli • I. Ferreira - A. Balasubramanian • \\ P. Dakin • P. Ho • S. Siddhanti • B. Stolshek • C. Recknor
}

Received: 31 December 2013 / Accepted: 21 August 2014 / Published online: 19 September 2014

(C) The Author(s) 2014. This article is published with open access at Springerlink.com

\begin{abstract}
Summary To determine persistence with subcutaneous denosumab every 6 months in women being treated for osteoporosis, we conducted a single-arm prospective, observational study in the United States and Canada. Among 935 patients enrolled, 12-month persistence was $82 \%$, with 66 patients (7\%) reporting serious adverse events and 19 patients (2\%) reporting fractures.

Introduction Increased persistence with osteoporosis therapy is associated with reduced fracture risk. Denosumab reduced fracture risk in clinical trials; persistence in community settings is undetermined. This study evaluates persistence with
\end{abstract}

Electronic supplementary material The online version of this article (doi:10.1007/s00198-014-2871-6) contains supplementary material, which is available to authorized users.

S. L. Silverman $(\bowtie)$

Cedars-Sinai Medical Center and OMC Clinical Research Center, 8641 Wilshire Blvd, Suite 301, Los Angeles, CA 90211, USA

e-mail: stuarts@omcresearch.org

E. Siris

Columbia University Medical Center, 180 Fort Washington Avenue, HP9-964, New York, NY 10032, USA

D. L. Kendler

University of British Columbia, Prohealth, 150-943 W Broadway,

Vancouver BC V5Z 4E1, Canada

D. Belazi

AlchemiPharma LLC, 678 Knox Rd, Wayne, PA 19087, USA

J. P. Brown

Laval University, CHU de Québec (CHUL) Research Center, Room

S-763, 2705 Laurier Boulevard, Quebec City QC G1V 4G2, Canada

D. T. Gold

Duke University Medical Center, Box 3003, Durham, NC 27710, USA denosumab in community practice in the United States (US) and Canada.

Methods In a 24-month multicenter, prospective, single-arm, observational study, women being treated for osteoporosis were enrolled $\leq 4$ weeks after the first subcutaneous injection of denosumab. For this 12-month prespecified interim analysis, endpoints include persistence (one injection at study entry and another within 6 months +8 weeks), attributes associated with persistence (univariate analysis), and serious adverse events (SAEs).

Results Among 935 patients (mean age 71 years), mean baseline $\mathrm{T}$-scores were -2.18 (femoral neck) and -2.00 (lumbar

E. M. Lewiecki

New Mexico Clinical Research \& Osteoporosis Center and University of New Mexico School of Medicine, 300 Oak St. NE, Albuquerque, NM 87106, USA

\section{A. Papaioannou}

McMaster University, Juravinski Research Center, Room 151, 88

Maplewood Avenue, Hamilton ON L8M 1W9, Canada

C. Simonelli

Health East Osteoporosis Care, 1875 Woodwinds Drive, Woodbury, MN 55125, USA

I. Ferreira

Amgen Limited, 240 Milton Road, Cambridge, UK CB4 0WD

A. Balasubramanian · P. Dakin · P. Ho · S. Siddhanti · B. Stolshek Amgen Inc., One Amgen Center Drive, Thousand Oaks, CA 91320, USA

C. Recknor

United Osteoporosis Centers, 2350 Limestone Pkwy, Gainesville, GA 30501, USA 
spine); $50 \%$ of patients had experienced osteoporotic fracture(s). At 12 months, $82 \%$ of patients were persistent with denosumab. Baseline factors significantly $(p<0.05)$ associated with higher persistence included use of osteoporosis medications $>5$ years previously, lumbar spine T-score $>-2.5$, and treatment by female physicians (US). Lower persistence was associated $(p<0.05)$ with psychiatric diagnoses including depression, southern US residence, being divorced, separated, or widowed (US), and prior hip fracture (Canada). SAEs were reported in 66 patients $(7 \%)$; no SAEs of osteonecrosis of the jaw, atypical femoral fracture, fracture healing complications, hypocalcemia, eczema, or hypersensitivity were reported. Nineteen patients $(2 \%)$ reported osteoporotic fractures.

Conclusions The 12-month persistence observed in this single-arm open-label study of US and Canadian community practice extends the evidence regarding denosumab's potential role in reducing fracture risk in postmenopausal women with osteoporosis.

Keywords Adherence - Compliance - Denosumab . Observational study $\cdot$ Osteoporosis $\cdot$ Persistence

\section{Introduction}

Osteoporotic fractures and the resulting morbidity and mortality are well documented [1-8], and the public health impact of these risks will likely increase as the population ages [9]. Osteoporosis therapies can reduce fracture risk; agents used include calcium and vitamin D supplements and prescription therapies. Prescription agents used in various regions include oral and intravenous bisphosphonates, oral strontium ranelate and raloxifene, subcutaneous denosumab and teriparatide, and intranasal calcitonin (US) $[10,11]$. Nonpersistence with osteoporosis therapy may increase fracture risk by up to $45 \%$ [12-17], particularly for patients at high risk of fracture; the associated rates of hospitalization and use of health care resources also increase [18].

Persistence, a widely used measure of treatment consistency, is defined by the International Society for Pharmacoeconomics and Outcomes Research (ISPOR) Medication Compliance and Persistence Work Group as the duration of time from initiation to discontinuation of therapy [19]. Measures of persistence may include a specific time period followed by a window of allowable delay, typically ranging from 30 to 90 days.

Numerous studies have examined persistence with oral bisphosphonates in patients being treated for osteoporosis, reporting 12-month persistence rates ranging from 12 to $61 \%[15-17,20]$. Fewer studies have assessed persistence with injected or infused medications. A UK observational database study of daily self-injected teriparatide $\left(\right.$ FORTEO $^{\circledR}$,
Eli Lilly and Company, Indianapolis, Indiana, USA), found that $87 \%$ of patients were persistent at 12 months [21], with persistence defined as the duration of treatment. Similarly, in a US observational study (Direct Analysis of Nonvertebral fractures in the Community Experience; DANCE), $86 \%$ of patients persisted with teriparatide treatment at 12 months [22]. Zoledronic acid Reclast $^{\circledR}{ }^{\circledR}$ or Aclasta ${ }^{\circledR}$, Novartis Pharmaceuticals Co., East Hanover, New Jersey, USA) is administered as an intravenous infusion every 1 or 2 years for the treatment or prevention of osteoporosis, respectively. In a 2011 clinical study of elderly patients in South Korea, 12-month persistence with zoledronic acid was $36 \%$ [23], and a US Medicare database analysis found that $68 \%$ of zoledronic acid recipients were persistent at 12 months [24]. In both studies, 12month persistence was defined as receiving a second scheduled infusion 12 months after the first infusion; no "window" or grace period before or after 12 months was reported in either study.

Denosumab (Prolia ${ }^{\circledR}$, Amgen Inc., Thousand Oaks, California, USA) is administered as a subcutaneous injection by a health care professional every 6 months to increase bone mass in men or treat osteoporosis in postmenopausal women at high risk of fracture $[25,26]$. In the DAPS study (Denosumab Adherence Preference Satisfaction), 250 patients who had received at least 6 months of alendronate $\left(\right.$ FOSAMAX $^{\circledR}$, Merck and Co., Inc., Whitehouse Station, New Jersey, USA) therapy were randomized to denosumab or oral alendronate for 12 months, then switched to the other treatment for another 12 months; study visits were scheduled every 6 months. Persistence was $90 \%$ with denosumab and $80 \%$ with alendronate at 12 months [27] and $97 \%$ with denosumab and $71 \%$ with alendronate following crossover at the end of the second 12 months [28].

Study of Transitioning from Alendronate to Denosumab (STAND) [29] and Determining Efficacy: Comparison of Initiating Denosumab versus Alendronate (DECIDE) [30] were randomized, double-blind, doubledummy studies that compared the effects of denosumab and alendronate on bone density and bone turnover markers. In these studies, persistence at 12 months was 94 and $93 \%$, respectively, with denosumab and 94 and $91 \%$, respectively, with alendronate. In the STAND and DECIDE denosumab clinical studies, patient visits were scheduled every 3 months.

These studies provide useful information from clinical trial settings, but evidence is lacking regarding persistence with denosumab in community practice. It is unknown whether persistence rates with denosumab are lower outside of clinical trials. The objectives of this study are to evaluate persistence with denosumab in postmenopausal women who received care in routine clinical practice in the US and Canada and to describe the patients who use denosumab in community settings. 


\section{Methods}

This is a prespecified interim analysis of data for the first 12 months of an ongoing multicenter, single-arm, prospective, observational, 24-month study being conducted in the US and Canada. Clinical sites include primary care and specialty practices caring for postmenopausal women with osteoporosis. Site selection was conducted by a team from the study sponsor who considered sites based on factors such as physician interest, availability of patients, presence of clinical staff, and execution of contracts. Physicians recruited patients during regular clinical visits. Participating patients are postmenopausal women who received denosumab for the treatment of osteoporosis according to the applicable US or Canadian prescribing information. The decision to use denosumab was made before the patient consented to participate in this study. Patients were excluded if they had participated in clinical trials of denosumab at any time or in any other clinical trial during the previous 6 months, or if they had any disorder that the investigator believed might compromise their ability to provide informed consent. Patients were enrolled within 4 weeks of receiving their first denosumab injection. No study-specific visits, clinical procedures, laboratory or diagnostic assessments, or changes to routine management of patients were required. All concomitant medications were allowed if they were deemed a necessary part of routine clinical care. An institutional review board (IRB) or ethics committee for each site approved the protocol and patients provided written informed consent before they were enrolled. Clinical sites at which women were treated for osteoporosis were selected from a pharmaceutical industry database to ensure a mix of practice types and physician specialties; the volume of denosumab prescriptions was not a consideration in selection of physicians or study sites.

\section{Data collected}

The data cutoff date for this prespecified interim analysis was December 31, 2012. A questionnaire was completed by each site to describe characteristics of the physician and site, including information about follow-up reminders sent to patients and reasons for prescribing denosumab.

Standard patient information for routine clinical care was recorded, including medical history, patient demographics, bone mineral density, fracture (osteoporotic or other), administrations of denosumab, previous and concomitant medical therapies, and comorbidities. Osteoporotic fractures were defined as all fractures excluding skull, facial bones, mandible, metacarpus, finger phalanges, toe phalanges, and cervical vertebrae, and not associated with known severe trauma (fall from higher than the height of stool, chair, first rung on a ladder or equivalent $[>20$ in], or severe trauma other than a fall) or pathological fractures. A comorbidity index adopting the Wolfe comorbidity index algorithm [31] (modified Wolfe comorbidity index) was calculated based on the responses related to the known history of comorbidities. Serious adverse events (SAEs) reported by physicians were recorded during the first year of the study; the protocol was subsequently amended to record all adverse events.

On the day of enrollment, patients were asked to complete a baseline questionnaire about their health history, including parental hip fractures, current and past smoking habits, alcohol consumption, and recent osteoporosis medication stoppages, as well as their income, education level, marital status, proximity to the treatment site, and use of a denosumab support program. The questionnaire also collected information regarding the type of health care coverage, prior authorization requirements, the denosumab co-payment, and for US patients enrolled in Medicare Part D (a government-sponsored prescription medication insurance plan for patients $\geq 65$ years of age and those with end-stage renal disease), the "donut hole" (a coverage gap after reaching a spending threshold during which patients pay a higher price for prescription medications) [32]. Patients also completed a patient-reported outcome instrument (SF-12) [33], the Preference and Satisfaction Questionnaire (PSQ) [34], and the Beliefs about Medicine Questionnaire (BMQ-S11) [35]. The SF-12 is a 12-item survey, with each item assessing broad measures of health status, and all 12 items adding up to 2 summary scales: Physical Component Summary and Mental Component Summary scores. The PSQ assesses patient preference and satisfaction with medication. The BMQ-S11 assesses positive and negative beliefs about specific prescribed medication and provides a numerical assessment of the way in which perceived benefit (necessity) is rated against perceived risk (concerns). Where permitted by regional laws or regulatory guidelines, patients could be compensated for inconvenience (e.g., completion of questionnaires).

\section{Study endpoints}

Study endpoints analyzed at 12 months in this 24-month study include persistence with denosumab at 12 months, defined as receipt of at least two injections, including one at study entry and a second no more than 6 months plus 8 weeks (239 days) later; medicine-taking behavior related to osteoporosis treatment over 12 months; and the occurrence of SAEs in the first 12 months plus 8 weeks. An 8 -week window was chosen because most persistence studies for oral osteoporosis treatments use a 30,60 , or 90 -day window [15]. The choice allowed for a sensitivity analysis within 4- to 12-week windows, as used in other studies. Also, it was thought to reflect patients in the real-world who would most likely begin thinking about returning for the next injection as the 6-month deadline approached and then would require about 2 months to make an appointment and secure prior authorization, if 
required. This allowable window is also consistent with the duration of action demonstrated for denosumab in the treatment of osteoporosis [36]. Additional analyses were conducted to identify baseline factors that had significant associations with persistence. Descriptive data were also analyzed to characterize the patients who used denosumab in community settings.

\section{Statistical analysis}

The analysis of persistence was based on total enrollment and included patients who discontinued denosumab treatment or withdrew from the study. Summary statistics were provided for subgroups based on patient demographic and socioeconomic characteristics, medical history, and characteristics of the physician, clinical site, or health care system. The planned enrollment was 600 patients from 60 sites in the US and 300 patients from 30 sites in Canada. The planned overall sample size of 900 patients would allow the half-width of the $95 \%$ confidence interval (CI) around the point estimate of overall persistence at the 12- and 24-month time points to be no greater than $3.3 \%$. Moreover, the half-width of the $95 \%$ CI would be no greater than $10 \%$ for most potential subgroups of interest, assuming a subgroup size of 60 patients and a persistence rate of $80 \%$; the half-width of the $95 \%$ CI would be $13 \%$ for a persistence rate of $50 \%$. Since enrollment was not stratified, the actual $95 \%$ CIs would depend on the actual population characteristics.

Baseline characteristics are summarized using descriptive statistics (frequency for categorical outcomes and number, mean, standard deviation [SD], median with interquartile ranges, or minimum and maximum values for continuous variables). Persistence rates were reported as percentages with $95 \% \mathrm{CI}$ values calculated using the exact method. Sensitivity analyses were used to examine different time windows for the definition of persistence. Data were analyzed for the overall study population and for individual countries. Univariate logistic regression analysis was used to explore association of baseline covariates with persistence in each country. In the univariate analysis, $p$ values express the statistical significance of each covariate across all subgroups. SAEs were coded using the Medical Dictionary for Regulatory Activities (MedDRA), tabulated by system organ class and preferred term, and summarized as subject incidence.

\section{Results}

Enrollment was completed in April 2012. A total of 942 patients agreed to join the study, of whom 935 (632 patients in the US, 303 in Canada) were enrolled; 7 did not meet eligibility criteria. At the time of data cutoff for the interim analysis, 817 patients $(87.4 \%)$ remained in the study (544 [86.1\%] in the US, and 273 [90.1\%] in Canada). Of the patients who discontinued the study, $55(5.9 \%)$ withdrew consent, $9(1.0 \%)$ were lost to follow-up, $8(0.9 \%)$ died, and $46(4.9 \%)$ cited other reasons, with similar distributions of reasons in both countries.

Patient demographic and physical characteristics

The mean (SD) age of study participants was 70.8 (9.9) years overall, and nearly three-quarters of patients were aged 65 or older (Table 1). US patients were slightly older than those in Canada (71.9 vs. 68.5 years). Most patients (94.8\%) in both the US and Canada were white or Caucasian. Patients had a mean (SD) body mass index (BMI) of $25.7(5.5) \mathrm{kg} / \mathrm{m}^{2}$; more patients in the US than in Canada had a BMI $\leq 25 \mathrm{~kg} / \mathrm{m}^{2}(49.5$ vs. $37.6 \%$ ). The mean (SD) femoral neck T-score was -2.18 (0.88) and was lower in the US than in Canada: $-2.33(0.77)$ vs. -1.87 (1.01), respectively. The overall mean (SD) lumbar spine T-score was -2.00 (1.31); in contrast with the femoral neck, T-scores for the lumbar spine were higher in the US than in Canada: -1.93 (1.34) vs. -2.13 (1.24), respectively (Table 1).

\section{Osteoporosis-related history}

Half of the patients in the study $(50.1 \%)$ had a history of osteoporotic fracture (Table 2). Nonvertebral fractures were the most common type, reported by $41.6 \%$ of patients; $15.9 \%$ of patients had vertebral fractures; and $6.5 \%$ of patients had a history of hip fracture. Parental hip fractures were reported by $21.0 \%$ of patients.

Nearly all patients $(92.0 \%)$ had received a prescription for osteoporosis medication during the 5 years before enrollment, and $58.5 \%$ had received a prescription for osteoporosis therapy more than 5 years before enrollment. The mean (SD) number of previous osteoporosis medications taken was 2.0 (1.3). Of treatments prescribed for osteoporosis in the last 5 years, the most common were alendronate, calcium supplements and vitamin D supplements, and risedronate (Table 2). Previous osteoporosis therapy use was different between countries, possibly because of differences in regulatory and reimbursement environments. Ibandronate had been used only in the US, by $20.3 \%$ of patients; similarly, etidronate had been used only in Canada, by $9.2 \%$ of patients. Additionally, risedronate had been used by $41.9 \%$ of patients in Canada but only $26.4 \%$ of US patients, and parathyroid hormone (PTH)/ teriparatide had been used by $23.7 \%$ of US patients but only $4.3 \%$ of those in Canada. 
Table 1 Patient demographic and physical characteristics

\begin{tabular}{|c|c|c|c|}
\hline Characteristic & $\begin{array}{l}\text { Overall } \\
N=935\end{array}$ & $\begin{array}{l}\mathrm{US} \\
N=632\end{array}$ & $\begin{array}{l}\text { Canada } \\
N=303\end{array}$ \\
\hline \multicolumn{4}{|l|}{ Age, years } \\
\hline Mean (SD) & $70.8(9.9)$ & $71.9(10.0)$ & $68.5(9.2)$ \\
\hline$<65, n(\%)$ & $267(28.6)$ & $152(24.1)$ & $115(38.0)$ \\
\hline 65 to $<75, n(\%)$ & $318(34.0)$ & $216(34.2)$ & $102(33.7)$ \\
\hline$\geq 75, n(\%)$ & $350(37.4)$ & $264(41.8)$ & $86(28.4)$ \\
\hline \multicolumn{4}{|l|}{ Race or ethnicity, $n(\%)$} \\
\hline White or Caucasian & $886(94.8)$ & $601(95.1)$ & $285(94.1)$ \\
\hline Asian & $25(2.7)$ & $9(1.4)$ & $16(5.3)$ \\
\hline Black or African American & $9(1.0)$ & $9(1.4)$ & $0(0.0)$ \\
\hline Other $^{\mathrm{a}}$ & $15(1.6)$ & $13(2.1)$ & $2(0.7)$ \\
\hline \multicolumn{4}{|l|}{ Marital status, $n(\%)$} \\
\hline Married & $512(54.8)$ & $320(50.6)$ & $192(63.4)$ \\
\hline Never married & $46(4.9)$ & $26(4.1)$ & $20(6.6)$ \\
\hline Divorced/separated/widowed & $373(39.9)$ & $282(44.6)$ & $91(30.0)$ \\
\hline Missing & $4(0.4)$ & $4(0.6)$ & $0(0.0)$ \\
\hline \multicolumn{4}{|l|}{ Body mass index } \\
\hline Mean (SD) & $25.7(5.5)$ & $25.4(5.7)$ & $26.2(5.0)$ \\
\hline$\leq 25 \mathrm{~kg} / \mathrm{m}^{2}, n(\%)$ & $427(45.7)$ & $313(49.5)$ & $114(37.6)$ \\
\hline$>25 \mathrm{~kg} / \mathrm{m}^{2}, n(\%)$ & $379(40.5)$ & $237(37.5)$ & $142(46.9)$ \\
\hline Missing, $n(\%)$ & $129(13.8)$ & $82(13.0)$ & $47(15.5)$ \\
\hline Modified Wolfe comorbidity index, median (Q1, Q3) & $2.0(1.0,3.0)$ & $2.0(1.0,3.0)$ & $2.0(1.0,3.0)$ \\
\hline Number of prescription medications taken at baseline, median (Q1, Q3) & $7.0(4.0,10.0)$ & $8.0(5.0,11.0)$ & $5.0(3.0,7.0)$ \\
\hline \multicolumn{4}{|l|}{ Baseline bone mineral density } \\
\hline \multicolumn{4}{|l|}{ Femoral neck T-score } \\
\hline Mean (SD) & $-2.18(0.88)$ & $-2.33(0.77)$ & $-1.87(1.01)$ \\
\hline$\leq-2.5, n(\%)$ & $351(37.5)$ & $272(43.0)$ & $79(26.1)$ \\
\hline$>-2.5, n(\%)$ & $508(54.3)$ & $313(49.5)$ & $195(64.4)$ \\
\hline Missing, $n(\%)$ & $76(8.1)$ & $47(7.4)$ & $29(9.6)$ \\
\hline \multicolumn{4}{|l|}{ Lumbar spine T-score } \\
\hline Mean (SD) & $-2.00(1.31)$ & $-1.93(1.34)$ & $-2.13(1.24)$ \\
\hline$\leq-2.5, n(\%)$ & $357(38.2)$ & $228(36.1)$ & $129(42.6)$ \\
\hline$>-2.5, n(\%)$ & $492(52.6)$ & $341(54.0)$ & $151(49.8)$ \\
\hline Missing, $n(\%)$ & $86(9.2)$ & $63(10.0)$ & $23(7.6)$ \\
\hline
\end{tabular}

$S D$ standard deviation, $Q 1, Q 3,25$ th and 75th percentile, US United States

${ }^{a}$ Other race includes mixed race, American Indian or Alaska Native, Native Hawaiian or other Pacific Islander, or other (not specified)

Persistence with denosumab

At 12 months, 766 patients (81.9; $95 \%$ CI 79.3-84.3) were persistent with denosumab; that is, they received a second denosumab injection within 6 months +8 weeks after the first injection (Fig. 1). Persistent patients included 501 (79.3\%) of those in the US and 265 (87.5\%) in Canada.

In sensitivity analyses, persistence increased as the window expanded. With a 4-week window, overall persistence was $74.8 \%(95 \%$ CI 71.8-77.5); with a 6-week window, persistence was $80.0 \%$ (95\% CI 77.3-82.5); with a 12 week window, persistence was $84.8 \%$ (95 \% CI 82.3-87.1).

Factors associated with persistence or nonpersistence

From the univariate analyses, several baseline factors showed a statistically significant association with persistence for patient subgroups; detailed data are reported in Table 3, and the list of all factors that were analyzed is presented in Supplementary Table S1. In the US, patient subgroups associated 
Table 2 Osteoporosis-related patient history and medication use

\begin{tabular}{|c|c|c|c|}
\hline Characteristic & $\begin{array}{l}\text { Overall } \\
N=935\end{array}$ & $\begin{array}{l}\text { US } \\
N=632\end{array}$ & $\begin{array}{l}\text { Canada } \\
N=303\end{array}$ \\
\hline Any history of fracture, $n(\%)$ & $525(56.1)$ & $361(57.1)$ & $164(54.1)$ \\
\hline Osteoporotic fracture, $n(\%)^{\mathrm{a}}$ & $468(50.1)$ & $324(51.3)$ & $144(47.5)$ \\
\hline Vertebral & $149(15.9)$ & $104(16.5)$ & $45(14.9)$ \\
\hline Nonvertebral & $389(41.6)$ & $270(42.7)$ & $119(39.3)$ \\
\hline Major nonvertebral $^{\mathrm{b}}$ & $261(27.9)$ & $178(28.2)$ & $83(27.4)$ \\
\hline Hip & $61(6.5)$ & $46(7.3)$ & $15(5.0)$ \\
\hline More than one fracture, $n(\%)$ & $246(26.3)$ & $173(27.4)$ & $73(24.1)$ \\
\hline \multicolumn{4}{|l|}{ Time since the most recent fractures, $n(\%)$} \\
\hline$<12$ months & $67(7.2)$ & $39(6.2)$ & $28(9.2)$ \\
\hline$\geq 12$ months & $456(48.8)$ & $320(50.6)$ & $136(44.9)$ \\
\hline Parent had hip fracture, $n(\%)$ & $196(21.0)$ & $127(20.1)$ & $69(22.8)$ \\
\hline \multicolumn{4}{|l|}{ Osteoporosis medication } \\
\hline Any exposure to prior prescription osteoporosis therapy prior to enrollment, $n(\%)$ & $867(92.7)$ & $587(92.9)$ & $280(92.4)$ \\
\hline Exposure to prior prescription osteoporosis therapy during the period $>5$ years prior to enrollment, $n(\%)$ & $547(58.5)$ & $360(57.0)$ & $187(61.7)$ \\
\hline Number of prior osteoporosis medications taken, mean (SD) & $2.0(1.3)$ & $2.0(1.3)$ & $2.0(1.2)$ \\
\hline \multicolumn{4}{|l|}{ Osteoporosis medications prescribed in the last 5 years, $n(\%)$} \\
\hline Alendronate & $398(42.6)$ & $255(40.3)$ & $143(47.2)$ \\
\hline Calcium supplements and vitamin D supplements & $376(40.2)$ & $232(36.7)$ & $144(47.5)$ \\
\hline Risedronate & $294(31.4)$ & $167(26.4)$ & $127(41.9)$ \\
\hline Zoledronic acid & $168(18.0)$ & $123(19.5)$ & $45(14.9)$ \\
\hline PTH/Teriparatide & $163(17.4)$ & $150(23.7)$ & $13(4.3)$ \\
\hline Ibandronate & $128(13.7)$ & $128(20.3)$ & $0(0.0)$ \\
\hline Hormone replacement therapy & $45(4.8)$ & $24(3.8)$ & $21(6.9)$ \\
\hline Raloxifene & $42(4.5)$ & $27(4.3)$ & $15(5.0)$ \\
\hline Other (non-bisphosphonate) & $31(3.3)$ & $26(4.1)$ & $5(1.7)$ \\
\hline Etidronate & $28(3.0)$ & $0(0.0)$ & $28(9.2)$ \\
\hline Calcitonin & $28(3.0)$ & $16(2.5)$ & $12(4.0)$ \\
\hline Other bisphosphonate & $6(0.6)$ & $3(0.5)$ & $3(1.0)$ \\
\hline Strontium ranelate & $2(0.2)$ & $0(0.0)$ & $2(0.7)$ \\
\hline
\end{tabular}

PTH parathyroid hormone, SERM selective estrogen receptor modulator, SD standard deviation, US United States

${ }^{a}$ Any fracture recorded on the case report form, excluding skull, facial bones, mandible, metacarpus, finger phalanges, toe phalanges, and cervical vertebrae and not associated with known severe trauma (fall from higher than the height of stool, chair, first rung on a ladder or equivalent [ $>20$ in], or severe trauma other than a fall) or pathological fractures

${ }^{\mathrm{b}}$ A subset of nonvertebral fractures including the following locations: pelvis, hip, lower leg (not knee or ankle), ribs, shoulder, forearm, and wrist and not associated with known severe trauma or pathological fractures

with higher persistence included those who used osteoporosis medications during the period more than 5 years before enrollment (83.3 vs. $73.9 \%$ ), patients with lumbar spine Tscores $>-2.5$ ( 82.7 vs. $75.9 \%$ for T-scores $\leq-2.5)$, and those treated by female physicians ( 85.1 vs. $77.3 \%$; Table 3 ). Patients whose BMQ-S11 necessity-concerns differential score (the ratio of beliefs about the necessity of treatment to concerns about potential negative aspects of treatment) was higher than the median score of 0.57 had a higher persistence rate $(83.9 \%)$ than those with scores below the median (76.5\%). Among the subgroups with lower persistence were US patients who reported depression or other psychiatric diagnoses at baseline compared with patients without these comorbidities (72.5 vs. $82.2 \%$ ); patients who were divorced, widowed, or separated $(74.5 \%)$ compared with those who were married ( $83.8 \%)$ or never married (76.9\%); and US residents from the South (72.2\%) compared with those from the Midwest $(87.0 \%)$, Northeast (83.3\%), and West (80.0\%).

Among Canadian patients, patients with a history of hip fracture had lower persistence $(60.0 \%)$ compared with those with no history of hip fracture $(88.9 \%)$. Those who selected the response not applicable (NA) to a question about the need for prior authorization had a lower rate of persistence $(65.0 \%)$ than those who responded yes $(87.9 \%)$ or no $(91.3 \%)$. 
Fig. 1 Persistence with denosumab at 12 months. a Primary analysis: percentage of patients who received a second injection of denosumab within 6 months +8 weeks. b Sensitivity analyses: percentage of patients who received a second injection of denosumab within 6 months + 4,6 , or 12 weeks. The dashed lines in $\mathbf{b}$ represent the proportion of patients who were persistent at the primary endpoint time window of 6 months +8 weeks. $N$ number of patients in the overall cohort and in each country. $n$ number of patients who were persistent in each group. $C I$ confidence interval, US United States a
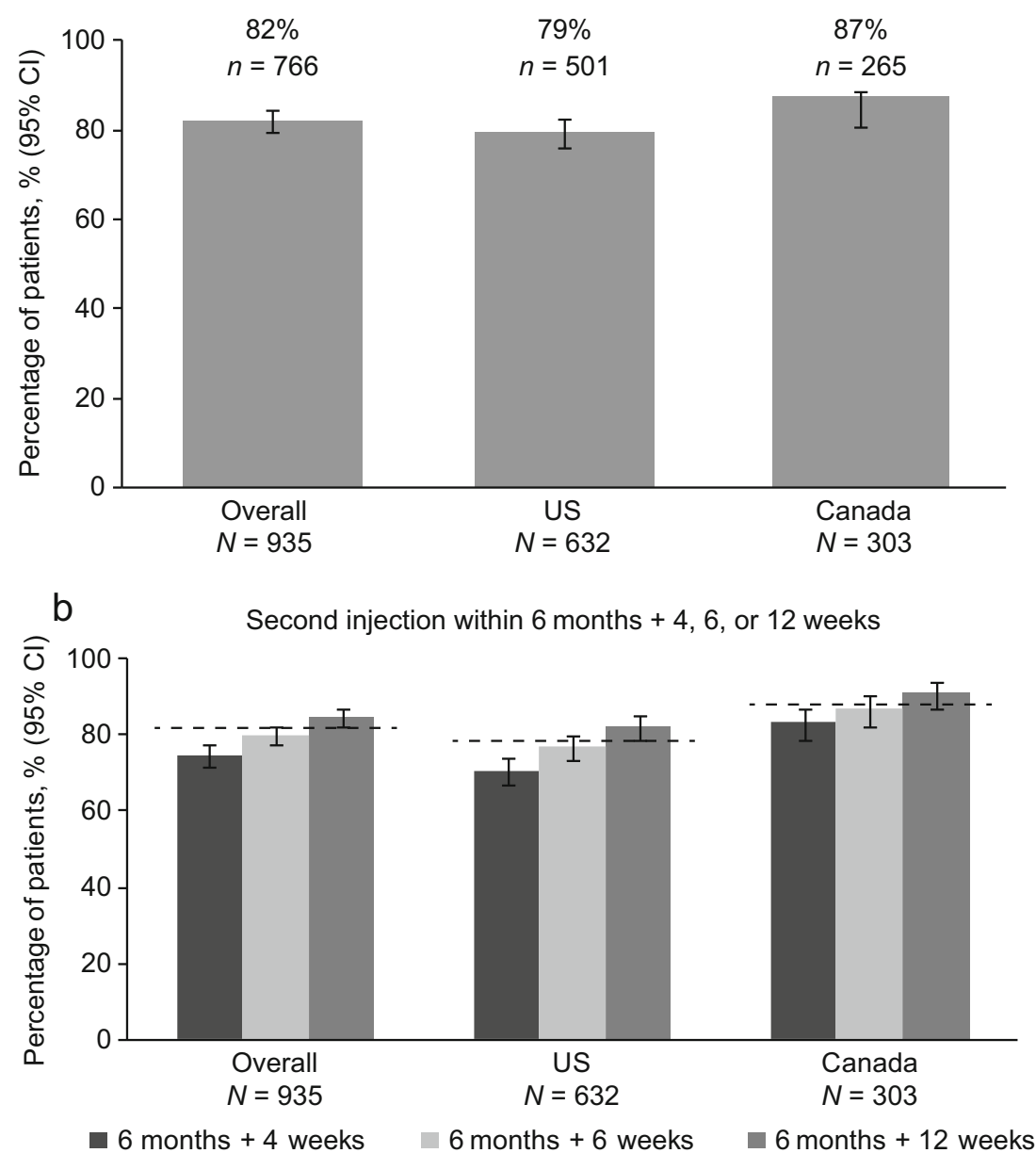

Comorbidities and risk factors

Osteoarthritis was the most common comorbidity, reported by $52.7 \%$ of the patients in this study (Supplementary Table S2). Hypertension and back pain were also reported by more than half of patients overall, and gastrointestinal disorders were reported by $44.9 \%$ of patients overall. The median (Q1, Q3) modified Wolfe comorbidity index in both the US and Canada was $2.0(1.0,3.0$; Table 1). Patients in the US were taking a median $(\mathrm{Q} 1, \mathrm{Q} 3)$ of $8.0(5.0,11.0)$ prescription medications at baseline, compared with $5.0(3.0,7.0)$ for patients in Canada.

Three key risk factors for osteoporotic fracture are age $\geq 65$ years, T-score $\leq-2.5$, and a history of osteoporotic fracture. In this study, nearly all patients $(93.9 \%)$ had at least one of these risk factors, 414 patients $(44.3 \%)$ had two of these risk factors, and 209 patients $(22.4 \%)$ had all three risk factors (Table 4). In this population, age was the largest contributor to overall risk; 668 of the 935 patients $(71.4 \%)$ in the study were aged $\geq 65$ years. The next most common risk factors were T-score $\leq-2.5$ at either the femoral neck or lumbar spine (574 patients, $61.4 \%$ ) and a history of osteoporotic fracture (468 patients, $50.1 \%$ ).
Physician and site characteristics

A total of 135 clinical sites were contacted, of which 80 sites enrolled at least 1 subject (US, 54; Canada, 26). Physician and site characteristics are described in Supplementary Table S3. The most common physician specialties were rheumatology $(n=22,41 \%)$ and internal medicine $(n=12,22 \%)$ in the US, and family practice $(n=8,31 \%)$ and endocrinology $(n=6$, $23 \%$ in Canada. Most physicians in both countries were men (US: $n=39,72 \%$; Canada: $n=19,73 \%$ ), were in private practices (US: $n=49,91 \%$; Canada: $n=20,77 \%$ ), and had at least 10 years of experience in practice (US: $n=47,87 \%$; Canada: $n=26,100 \%$ ). Two-thirds of physicians in the US $(n=36,67 \%)$ and half in Canada $(n=13,50 \%)$ were in group practices; the others were sole practitioners.

Reasons for prescribing denosumab

Among all patients in the study, the most common reason for prescribing denosumab was that the patient had multiple risk factors for fracture (as defined by the physician), cited by $54.1 \%$ of physicians (Supplementary Table S4). Other reasons included 
Table 3 Baseline factors that show statistically significant association with persistence by country

\begin{tabular}{|c|c|c|c|c|c|}
\hline Country & Covariate & Category & Persistence $(\%)$ & Odds ratio $(95 \% \mathrm{CI})$ & $p$ value \\
\hline \multirow[t]{17}{*}{ US } & \multirow{2}{*}{$\begin{array}{l}\text { Depression and/or other } \\
\text { psychiatric diagnoses }\end{array}$} & No & 82.2 & Reference & \multirow[t]{2}{*}{0.0062} \\
\hline & & Yes & 72.5 & $0.569(0.380-0.852)$ & \\
\hline & \multirow{2}{*}{$\begin{array}{l}\text { Use of osteoporosis medications }>5 \\
\text { years before enrollment }\end{array}$} & Yes & 83.3 & $1.766(1.199-2.602)$ & \multirow[t]{2}{*}{0.0040} \\
\hline & & No & 73.9 & Reference & \\
\hline & \multirow[t]{2}{*}{ Lumbar spine BMD T-score } & $>-2.5$ & 82.7 & Reference & \multirow[t]{2}{*}{0.0472} \\
\hline & & $\leq-2.5$ & 75.9 & $0.658(0.435-0.995)$ & \\
\hline & \multirow[t]{4}{*}{ Region } & Midwest & 87.0 & $1.338(0.624-2.871)$ & \multirow[t]{4}{*}{0.0143} \\
\hline & & Northeast & 83.3 & Reference & \\
\hline & & West & 80.0 & $0.800(0.442-1.448)$ & \\
\hline & & South & 72.2 & $0.520(0.290-0.931)$ & \\
\hline & \multirow[t]{2}{*}{ Physician gender } & Female & 85.1 & $1.678(1.034-2.723)$ & \multirow[t]{2}{*}{0.0362} \\
\hline & & Male & 77.3 & Reference & \\
\hline & \multirow[t]{3}{*}{ Marital status } & Married & 83.8 & Reference & \multirow[t]{3}{*}{0.0197} \\
\hline & & Never married & 76.9 & $0.647(0.248-1.689)$ & \\
\hline & & Divorced/ separated/ widowed & 74.5 & $0.566(0.379-0.844)$ & \\
\hline & \multirow{2}{*}{$\begin{array}{l}\text { BMQ-S11 necessity-concerns } \\
\quad \text { differential score }(\text { median }=0.57)\end{array}$} & $\leq$ Median & 76.5 & Reference & \multirow[t]{2}{*}{0.0244} \\
\hline & & $>$ Median & 83.9 & $1.599(1.062-2.406)$ & \\
\hline \multirow[t]{5}{*}{ Canada } & \multirow[t]{2}{*}{ Prior hip fracture } & No & 88.9 & Reference & \multirow[t]{2}{*}{0.0028} \\
\hline & & Yes & 60.0 & $0.187(0.063-0.561)$ & \\
\hline & \multirow[t]{3}{*}{ Need for prior authorization ${ }^{a}$} & No & 91.3 & Reference & \multirow[t]{3}{*}{0.008} \\
\hline & & Yes & 87.9 & $0.688(0.306-1.545)$ & \\
\hline & & NA & 65.0 & $0.176(0.058-0.533)$ & \\
\hline
\end{tabular}

Univariate analysis. The $p$ value represents the statistical significance of the covariate when added to the univariate logistic model, with persistence as the response variable

BMQ-S11 Beliefs About Medicine Questionnaire, CI confidence interval, NA not applicable, US United States

${ }^{\text {a }}$ Statistically significant because of large number of patients in NA category

failure of other available osteoporosis therapies (42.4\%), patient intolerance of other osteoporosis therapies (32.0\%), and a history of osteoporotic fracture $(29.3 \%)$. More than one reason could be cited for prescribing denosumab for each patient.

Table 4 Risk factors for osteoporosis

\begin{tabular}{|c|c|c|c|}
\hline Risk factors, $n(\%)$ & $\begin{array}{l}\text { Overall } \\
N=935\end{array}$ & $\begin{array}{l}\text { US } \\
N=632\end{array}$ & $\begin{array}{l}\text { Canada } \\
N=303\end{array}$ \\
\hline Age $\geq 65$ years & $668(71.4)$ & $480(75.9)$ & $188(62.0)$ \\
\hline $\mathrm{T}$-score $\leq-2.5^{\mathrm{a}}$ & $574(61.4)$ & $394(62.3)$ & $180(59.4)$ \\
\hline$\geq 1$ historical osteoporotic fracture ${ }^{\mathrm{b}}$ & $468(50.1)$ & $324(51.3)$ & $144(47.5)$ \\
\hline \multicolumn{4}{|l|}{ Number of risk factors } \\
\hline 0 & $57(6.1)$ & $26(4.1)$ & $31(10.2)$ \\
\hline 1 of the following risk factors: & $255(27.3)$ & $159(25.2)$ & $96(31.7)$ \\
\hline Age $\geq 65$ years old & $118(12.6)$ & $84(13.3)$ & $34(11.2)$ \\
\hline T-score $\leq-2.5^{\mathrm{a}}$ & $99(10.6)$ & $53(8.4)$ & $46(15.2)$ \\
\hline$\geq 1$ historical osteoporotic fracture ${ }^{\mathrm{b}}$ & $38(4.1)$ & $22(3.5)$ & $16(5.3)$ \\
\hline 2 of the following risk factors: & $414(44.3)$ & $302(47.8)$ & $112(37.0)$ \\
\hline Age $\geq 65$ years old and T-score $\leq-2.5^{\mathrm{a}}$ & $193(20.6)$ & $145(22.9)$ & $48(15.8)$ \\
\hline Age $\geq 65$ years old and $\geq 1$ historical osteoporotic fracture ${ }^{b}$ & $148(15.8)$ & $106(16.8)$ & $42(13.9)$ \\
\hline $\mathrm{T}$-score $\leq-2.5^{\mathrm{a}}$ and $\geq 1$ historical osteoporotic fracture ${ }^{\mathrm{b}}$ & $73(7.8)$ & $51(8.1)$ & $22(7.3)$ \\
\hline $\begin{array}{l}3 \text { risk factors (age } \geq 65 \text { years old, T-score } \leq-2.5 \\
\text { and } \geq 1 \text { historical osteoporotic fracture) }\end{array}$ & $209(22.4)$ & $145(22.9)$ & $64(21.1)$ \\
\hline
\end{tabular}

\section{US United States}

${ }^{\mathrm{a}} \mathrm{T}$-score at femoral neck or lumbar spine

${ }^{\mathrm{b}}$ Any fracture recorded on the case report form, excluding skull, facial bones, mandible, metacarpus, finger phalanges, toe phalanges, and cervical vertebrae and not associated with known severe trauma (fall from higher than the height of stool, chair, first rung on a ladder or equivalent [ $>20$ in] or severe trauma other than a fall) or pathological fractures 
Among patients with none of the three key risk factors for osteoporotic fracture (age $\geq 65$ years, T-score $\leq-2.5$, and a history of osteoporotic fracture), physicians cited multiple risk factors for fracture (as defined by the physician) as a reason for prescribing denosumab for $61.4 \%$ of patients; failure of other osteoporosis therapies $(35.1 \%)$ and intolerance of other osteoporosis therapies $(28.1 \%)$ were also cited.

\section{Safety}

SAEs were reported for 66 patients $(7.1 \%)$, including 51 $(8.1 \%)$ in the US and $15(5 \%)$ in Canada (Table 5). Five patients reported SAEs $(0.5 \%)$ that led to discontinuation of denosumab. Three patients $(0.3 \%)$ had SAEs that led to withdrawal from the study. Nine patients $(1.0 \%)$ had fatal SAEs, none of which were considered related to denosumab by the investigator. Of these, fatal SAEs of infection occurred in five patients: two cases of Clostridium difficile colitis (one with a history of ulcerative colitis and past history of $C$. difficile infection; one with chronic diarrhea, chronic pancreatitis, and chronic renal failure and possible pneumonia); one case of device-related sepsis (the patient was hospitalized for digoxin toxicity requiring hemodialysis for acute renal failure); one event of pneumonia (in the context of underlying chronic obstructive pulmonary disease [COPD]); and a local hand infection with subsequent progression to necrotizing fasciitis with protracted course in a patient with multiple comorbidities including diabetes mellitus and past medical history that included shingles, arm abscess, and gluteal furuncle. Four additional fatalities included two patients with histories of ovarian cancer who died of metastatic cancer, and one patient with

Table 5 Serious adverse events and fractures

\begin{tabular}{lrrr}
\hline Event, patient incidence, $n$ (\%) & $\begin{array}{r}\text { Overall } \\
N=935\end{array}$ & $\begin{array}{l}\text { US } \\
N=632\end{array}$ & $\begin{array}{r}\text { Canada } \\
N=303\end{array}$ \\
\hline All SAEs & $66(7.1)$ & $51(8.1)$ & $15(5.0)$ \\
$\quad \begin{array}{l}\text { SAEs leading to discontinuation } \\
\text { of denosumab }\end{array}$ & $5(0.5)$ & $3(0.5)$ & $2(0.7)$ \\
$\begin{array}{l}\text { SAEs leading to withdrawal from } \\
\text { the study }\end{array}$ & $3(0.3)$ & $3(0.5)$ & $0(0.0)$ \\
$\begin{array}{l}\text { Fatal adverse events } \\
\text { Osteoporotic fractures }\end{array}$ & $9(1.0)$ & $7(1.1)$ & $2(0.7)$ \\
\hline
\end{tabular}

SAE serious adverse event, US United States

${ }^{a}$ One death, which occurred after the data cut-off for this analysis, resulted from an SAE that began during the interim data analysis period

${ }^{\mathrm{b}}$ Any fracture recorded on the case report form, excluding skull, facial bones, mandible, metacarpus, finger phalanges, toe phalanges, and cervical vertebrae and not associated with known severe trauma (fall from higher than the height of stool, chair, first rung on a ladder or equivalent [ $>20$ in] or severe trauma other than a fall) or pathological fractures

${ }^{\mathrm{c}}$ On-study osteoporotic fractures were as follows: 1 carpus, 2 fibula, 2 humerus, 5 spine, 5 metatarsus, 2 patella, 1 pubis, 2 radius, 1 rib, 5 tarsus, 1 tibia underlying coronary artery disease, congestive heart failure, and COPD who died from cardiac arrest. The death of a 92year-old patient was reported to be from natural causes.

Fracture data were collected as adverse events and review of radiographs was not adjudicated. Nineteen patients experienced a total of 27 osteoporotic fractures (Table 5). Of the patients who experienced osteoporotic fractures during the study, $13(68.4 \%)$ had a history of prior osteoporotic fracture.

There were no reports of atypical femoral fracture or osteonecrosis of the jaw, or SAEs of fracture healing complications, hypocalcemia, eczema, or hypersensitivity.

\section{Discussion}

This analysis reports 12-month interim data from a prospective, observational, single-arm, open-label study of postmenopausal women in the US and Canada who received denosumab for treatment of osteoporosis as part of routine clinical care in accordance with the local approved label. More than $80 \%$ of these patients were persistent with their second injection of denosumab therapy. Univariate analyses of factors associated positively with higher or lower persistence in the first year varied widely and were different between the US and Canada. Safety results in this study were consistent with those observed in previous studies of denosumab, and no new safety signals were identified. The types of SAEs identified reflect complex medical histories of study participants at high risk for fracture who were enrolled in this observational evaluation.

The importance of persistence in reducing fracture risk has been established [12-17]. Multiple studies have provided data regarding 12-month persistence for other oral, infused, and injected osteoporosis therapies [15, 17, 20-24]. Additionally, 12-month persistence with denosumab was reported from three randomized controlled clinical trials [27, 28, 30]. The current observational study contributes needed evidence regarding the willingness of patients to persist with denosumab treatment outside the setting of a clinical trial, in routine community practice. In our study, persistence with denosumab at 12 months was $82 \%$, a relatively small difference from the 90,94 , and $93 \%$ rates observed at 12 months in the DAPS, STAND, and DECIDE clinical studies of denosumab [27, 29, $30]$. In contrast, rates of 12-month persistence with oral bisphosphonates in community settings have been reported to range from 12 to $61 \%[14,17]$.

In comparison, studies of injected teriparatide found 12month persistence rates of 86 and $87 \%$ [21, 22]. Several factors contribute to these high rates of persistence. In the 2006 report of the UK teriparatide study, the authors noted that patients cannot receive teriparatide in the UK health care system unless they have sustained several fractures, have failed or have been intolerant to a bisphosphonate, received the prescription from a specialist, and participated in an 
education and nurse-led follow-up program; these restrictions might contribute to a selected population that may be more inclined to be persistent than other patients [21]. In the 2011 study of US patients, Gold et al. [22] noted that $59 \%$ of patients believed their osteoporosis was severe or very severe, $96 \%$ believed it was very or extremely important to treat their osteoporosis, and $84 \%$ believed that teriparatide would be very or extremely effective in reducing fracture risk; these factors were thought to have contributed to high levels of persistence. Some patients participated in an optional patient support program, which might also have affected persistence. Additionally, the authors noted that many of the study investigators in the DANCE study were considered national experts who might not be representative of other prescribers. These factors complicate comparison between the denosumab and teriparatide persistence rates.

Two studies of infused zoledronic acid for osteoporosis found persistence rates of 36 and $68 \%$ at 12 months [23, 24]. Neither of these zoledronic acid studies specifically analyzed variations in community practices or the effects of 2-year dosing for prevention, an approved indication in some regions, so these data may not reflect current community practice.

Since few studies have evaluated persistence in infrequently injected treatments such as denosumab, there is little precedent for the methods used to define persistence. In the studies of daily teriparatide, definitions of persistence were simple - the duration of treatment [21] and not reporting discontinuation [22]. In the DAPS study, persistence with denosumab was defined as receiving two injections and completing the treatment period [27]. In our study, the endpoint of persistence allowed for a window of 8 weeks following the 6month treatment interval. This allowable window is consistent with the duration of action demonstrated for denosumab in the treatment of osteoporosis [36]. The 8-week window also recognizes that many patients would most likely begin thinking about returning for the next injection as the 6-month deadline approached and then would need about 2 months to make an appointment and secure prior authorization, if required. However, sensitivity analyses of results for windows of 6 months $+4,6$, or 12 weeks showed only minor differences in persistence results.

Three key risk factors for osteoporotic fracture are age $\geq 65$ years, T-score $\leq-2.5$, and a history of osteoporotic fracture $[11,37]$. Whether these risk factors are associated with persistence has been inconsistent. The effects of both age and previous fracture have varied among studies [38]. In this study, age did not appear to be associated with persistence based on statistical significance from a univariate analysis; similarly, previous hip fracture and lower T-scores were not associated with higher persistence. As might be expected, depression and/or other psychiatric diagnoses were associated with a lower rate of persistence for US patients, but this relationship was not significant in Canada. In some subgroups of patients, such as those who used bisphosphonates during the period more than 5 years before enrollment, patients treated by female physicians, those residing in specific regions, and married patients, persistence was surprisingly high compared with other subgroups - but even these were inconsistent between the US and Canada. Except for the physician's gender, factors related to the physician or medical practice (e.g., specialty or use of reminders) were not statistically significantly associated with persistence, perhaps due to the high rate of overall persistence.

Schousboe argues that patients' beliefs, concerns, and satisfaction with treatments are major contributors to persistence; he contends that more study is needed to understand these factors [38]. Some studies have recently addressed that need. Barrett-Connor et al. [39] confirmed the role of patient satisfaction in persistence with osteoporosis treatment. Kendler et al. [40] explored the influence on persistence of patients' beliefs about their personal need for osteoporosis treatment and their potential concerns about possible adverse consequences for taking it. The authors found a higher degree of belief in the necessity of osteoporosis medication and a lower degree of concern about adverse consequences (the necessityconcerns differential score) were associated with better adherence in some time periods measured. In that study, preference for denosumab vs. alendronate was associated with higher persistence. In the current analysis, a greater necessityconcerns differential score had a higher odds ratio for persistence for US patients. Patients in our observational study had already declared their preference for denosumab when they decided to receive treatment prior to study enrollment. More research is needed to identify factors that will influence patients to persist with osteoporosis therapy. In view of the compelling research linking persistence and compliance to reduction of fractures, this research is critical. In addition, primary nonadherence (the initial refusal of the recommendation to begin fracture prevention medication) is another important topic that warrants further study. In particular, the characteristics of those who fall into this category need to be explicated.

This study has some limitations. The analysis of factors associated with persistence is not easy to interpret or to apply in clinical practice or policy decision-making. This 12-month analysis was not designed to evaluate the interactions between 12-month persistence and the risk of fracture due to the observational nature and short time frame of this analysis. Because neither physicians nor patients were asked the reasons for delay or discontinuation, potential reasons (e.g., patient illness and switch to another treatment) are unknown. It is possible that physicians who participated in this study were not representative of the overall population of physicians who treat women with osteoporosis. For example, physicians in this study were interested in participating in research, and their practices had the infrastructure to do so, which may not 
be the case for all physicians and sites. These physicians began enrolling patients beginning a year following the availability of denosumab and may have been early users of the product. This fact may suggest actions that may be used in some offices to encourage patient return that were not captured in the physician site survey. Similarly, the patients in this study might not have been representative of the overall population in that they were willing to participate in a research study. Also, the patients in these studies knew in advance that their medication use behavior was being observed, unlike retrospective studies of pharmaceutical claims databases. They were candidates for, and approximately half participated in, a voluntary denosumab patient support program, potentially benefiting their persistence in the study; the influence of such programs is unknown. The reimbursement landscape differences between the US and Canada may explain some of the differences in persistence between the countries. However, because reimbursement systems varied between the US and Canada and among regions in each country, the effects of reimbursement and cost-sharing systems could not be precisely assessed. Regarding safety, decreased surveillance in routine clinical practice compared with randomized, controlled clinical trials may have impacted the SAEs reported.

These limitations do not outweigh the strengths of this study, which include the prospective observational design and the wide range of practice types, North American regions, and patients represented in the study. While the results may not be generalizable to all patients, they are more likely than clinical trial analyses of persistence to provide insights into real-world use of twice-yearly denosumab therapy.

Overall, this study provides important new evidence concerning persistence with denosumab therapy in community practice settings. Whereas persistence with oral osteoporosis treatments has been analyzed, limited data are available for an injected twice-yearly medication. Future studies should consider the relationship between persistence with denosumab and the incidence of fracture, perhaps in comparison with other osteoporosis therapies. The study lays the groundwork for such additional research to clarify the factors that would increase persistence among denosumab users and thereby reduce the risk of fractures in women with osteoporosis.

Acknowledgments This study was funded by Amgen Inc. The authors acknowledge the medical writing assistance of Michelle N. Bradley of Amgen Inc. and Sue Hudson, whose services were funded by Amgen Inc.

Conflicts of interest S.L. Silverman: research grants from Amgen, speakers' bureau member, consultant, and national advisory board member for Amgen. E. Siris: consulting fees from Amgen, Eli Lilly, Merck, Novartis, and Pfizer. Member of Governance Committee of the National Bone and Health Alliance. D.L. Kendler: research grants and consulting fees from, and member of speakers' bureaus for Amgen, Eli Lilly, Novartis, Pfizer, GlaxoSmithKline, and has received research grants from Johnson \& Johnson. D. Belazi: consulting fees from Amgen and Eli Lilly.
J.P. Brown: research grants from Abbott, Amgen, Bristol-Myers-Squibb, Eli Lilly, Merck, Novartis, Roche, sanofi-aventis, Servier, Takeda, and Warner Chilcott. Consulting fees from Amgen, Eli Lilly, Merck, Novartis, sanofi-aventis, and Warner Chilcott. Member of speakers' bureaus for Amgen, Eli Lilly, Novartis, and Merck. D.T. Gold: consulting fees from and member of the speakers' bureau for Amgen and Eli Lilly. E.M. Lewiecki: Research grants from and on scientific advisory boards for Amgen, Eli Lilly, and Merck. He has also served on speakers' bureaus for Amgen, Eli Lilly, and Novartis. Board member of the National Osteoporosis Foundation, the United States Bone and Joint Initiative, and the International Society for Clinical Densitometry. A. Papaioannou: Research grants, speakers' bureaus, and consulting fees from Amgen, Eli Lilly, and Merck Canada. She has also received research grants from Warner Chilcott. C. Simonelli: Research grants and consulting fees from, and served on speakers' bureaus for Amgen and Eli Lilly. C. Recknor: Consulting and advisory fees from Amgen, Eli Lilly, and Novartis, lecture fees from Novartis and Warner Chilcott, and research grants from Medi and is a shareholder in Ion Med Systems. I. Ferreira, A. Balasubramanian, P. Dakin, P. Ho, S. Siddhanti, and B. Stolshek: Employees of Amgen and have received Amgen stock/stock options.

Open Access This article is distributed under the terms of the Creative Commons Attribution Noncommercial License which permits any noncommercial use, distribution, and reproduction in any medium, provided the original author(s) and the source are credited.

\section{References}

1. NIH Consensus Development Panel on Osteoporosis Prevention D, and Therapy (2001) Osteoporosis prevention, diagnosis, and therapy. JAMA 285:785-795

2. European Foundation for Osteoporosis and Bone Disease, National Osteoporosis Foundation of the USA (1997) Who are candidates for prevention and treatment for osteoporosis? Osteoporos Int 7:1-6

3. Bliuc D, Nguyen ND, Nguyen TV, Eisman JA, Center JR (2013) Compound risk of high mortality following osteoporotic fracture and re-fracture in elderly women and men. J Bone Miner Res 28:23172324

4. Cummings SR, Melton LJ (2002) Epidemiology and outcomes of osteoporotic fractures. Lancet 359:1761-1767

5. Jacques RM, Boonen S, Cosman F, Reid IR, Bauer DC, Black DM, Eastell R (2012) Relationship of changes in total hip bone mineral density to vertebral and nonvertebral fracture risk in women with postmenopausal osteoporosis treated with once-yearly zoledronic acid $5 \mathrm{mg}$ : the HORIZON-Pivotal Fracture Trial (PFT). J Bone Miner Res 27:1627-1634

6. Johnell O, Kanis JA (2006) An estimate of the worldwide prevalence and disability associated with osteoporotic fractures. Osteoporos Int 17:1726-1733

7. Nguyen ND, Ahlborg HG, Center JR, Eisman JA, Nguyen TV (2007) Residual lifetime risk of fractures in women and men. J Bone Miner Res 22:781-788

8. Melton LJ 3rd, Achenbach SJ, Atkinson EJ, Therneau TM, Amin S (2013) Long-term mortality following fractures at different skeletal sites: a population-based cohort study. Osteoporos Int 24:1689-1696

9. U.S. Department of Health and Human Services (2004) Bone health and osteoporosis: A report of the surgeon general. U.S. Department of Health and Human Services. http://www.surgeongeneral.gov/ library/reports/bonehealth/

10. Levis S, Theodore G (2012) Summary of AHRQ's comparative effectiveness review of treatment to prevent fractures in men and women with low bone density or osteoporosis: update of the 2007 report. J Manag Care Pharm 18:S1-S15, discussion S13 
11. National Osteoporosis Foundation (2013) Clinician's guide to prevention and treatment of osteoporosis. National Osteoporosis Foundation. http://nof.org/hcp/clinicians-guide. Accessed 25 Aug, 2013

12. Halpern R, Becker L, Iqbal SU, Kazis LE, Macarios D, Badamgarav E (2011) The association of adherence to osteoporosis therapies with fracture, all-cause medical costs, and all-cause hospitalizations: a retrospective claims analysis of female health plan enrollees with osteoporosis. J Manag Care Pharm 17:25-39

13. Ross S, Samuels E, Gairy K, Iqbal S, Badamgarav E, Siris E (2011) A meta-analysis of osteoporotic fracture risk with medication nonadherence. Value Health 14:571-581

14. Siris ES, Harris ST, Rosen CJ, Barr CE, Arvesen JN, Abbott TA, Silverman S (2006) Adherence to bisphosphonate therapy and fracture rates in osteoporotic women: relationship to vertebral and nonvertebral fractures from 2 US claims databases. Mayo Clin Proc 81:1013-1022

15. Siris ES, Selby PL, Saag KG, Borgstrom F, Herings RM, Silverman SL (2009) Impact of osteoporosis treatment adherence on fracture rates in North America and Europe. Am J Med 122:S3-S13

16. Siris ES, Pasquale MK, Wang Y, Watts NB (2011) Estimating bisphosphonate use and fracture reduction among US women aged 45 years and older, 2001-2008. J Bone Miner Res 26:3-11

17. Wade SW, Curtis JR, Yu J, White J, Stolshek BS, Merinar C, Balasubramanian A, Kallich JD, Adams JL, Viswanathan HN (2012) Medication adherence and fracture risk among patients on bisphosphonate therapy in a large United States health plan. Bone 50: $870-875$

18. Huybrechts KF, Ishak KJ, Caro JJ (2006) Assessment of compliance with osteoporosis treatment and its consequences in a managed care population. Bone 38:922-928

19. Cramer JA, Roy A, Burrell A, Fairchild CJ, Fuldeore MJ, Ollendorf DA, Wong PK (2008) Medication compliance and persistence: terminology and definitions. Value Health 11:44-47

20. Kothawala P, Badamgarav E, Ryu S, Miller RM, Halbert RJ (2007) Systematic review and meta-analysis of real-world adherence to drug therapy for osteoporosis. Mayo Clin Proc 82:1493-1501

21. Arden NK, Earl S, Fisher DJ, Cooper C, Carruthers S, Goater M (2006) Persistence with teriparatide in patients with osteoporosis: the UK experience. Osteoporos Int 17:1626-1629

22. Gold DT, Weinstein DL, Pohl G, Krohn KD, Chen Y, Meadows ES (2011) Factors associated with persistence with teriparatide therapy: results from the DANCE observational study. J Osteoporos 2011: 314970

23. Lee YK, Nho JH, Ha YC, Koo KH (2012) Persistence with intravenous zoledronate in elderly patients with osteoporosis. Osteoporos Int 23:2329-2333

24. Curtis JR, Yun H, Matthews R, Saag KG, Delzell E (2012) Adherence with intravenous zoledronate and intravenous ibandronate in the United States Medicare population. Arthritis Care Res (Hoboken) 64:1054-1060

25. Amgen Canada Inc. Prolia ${ }^{\circledR}$ (denosumab) solution for injection. Product monograph. September 5, 2013. http://www.amgen.ca/ Prolia_PM.pdf. Accessed 1 Dec 2013

26. Amgen Inc. Prolia ${ }^{\circledR}$ (denosumab) injection. U.S. full prescribing information, July 2013. http://pi.amgen.com/united_states/prolia/ prolia_pi.pdf. Accessed 1 Dec 2013
27. Kendler DL, McClung MR, Freemantle N et al (2011) Adherence, preference, and satisfaction of postmenopausal women taking denosumab or alendronate. Osteoporos Int 22:1725-1735

28. Freemantle N, Satram-Hoang S, Tang ET, Kaur P, Macarios D, Siddhanti S, Borenstein J, Kendler DL, Investigators D (2012) Final results of the DAPS (Denosumab Adherence Preference Satisfaction) study: a 24-month, randomized, crossover comparison with alendronate in postmenopausal women. Osteoporos Int 23:317326

29. Kendler DL, Roux C, Benhamou CL, Brown JP, Lillestol M, Siddhanti S, Man HS, San Martin J, Bone HG (2010) Effects of denosumab on bone mineral density and bone turnover in postmenopausal women transitioning from alendronate therapy. J Bone Miner Res 25:72-81

30. Brown JP, Prince RL, Deal C et al (2009) Comparison of the effect of denosumab and alendronate on BMD and biochemical markers of bone turnover in postmenopausal women with low bone mass: a randomized, blinded, phase 3 trial. J Bone Miner Res 24:153-161

31. Wolfe F, Michaud K, Li T, Katz RS (2010) Chronic conditions and health problems in rheumatic diseases: comparisons with rheumatoid arthritis, noninflammatory rheumatic disorders, systemic lupus erythematosus, and fibromyalgia. J Rheumatol 37:305-315

32. Costs in the coverage gap. Center for Medicare and Medicaid Services. http://www.medicare.gov/part-d/costs/coverage-gap/partd-coverage-gap.html. Accessed 2 Nov 2013

33. Ware JE Jr, Kosinksi M, Turner-Bowker DM, Ganedek B (2002) How to score version 2 of the SF-12 health survey. QualyMetric, Lincoln

34. Gold DT, Horne R, Coon CD, Price MA, Borenstein J, Varon SF, Satram-Hoang S, Macarios D (2011) Development, reliability, and validity of a new Preference and Satisfaction Questionnaire. Value Health 14:1109-1116

35. Horne R, Weinman J (1999) Patients' beliefs about prescribed medicines and their role in adherence to treatment in chronic physical illness. J Psychosom Res 47:555-567

36. Bone HG, Bolognese MA, Yuen CK, Kendler DL, Miller PD, Yang YC, Grazette L, San Martin J, Gallagher JC (2011) Effects of denosumab treatment and discontinuation on bone mineral density and bone turnover markers in postmenopausal women with low bone mass. J Clin Endocrinol Metab 96:972-980

37. Kanis JA, World Health Organization Scientific Group (2007) Assessment of osteoporosis at the primary care health level. Technical Report. WHO Collaborating Centre for Metabolic Bone Diseases, University of Sheffield, UK

38. Schousboe JT (2013) Adherence with medications used to treat osteoporosis: behavioral insights. Curr Osteoporos Rep 11: 21-29

39. Barrett-Connor E, Wade SW, Do TP, Satram-Hoang S, Stewart R, Gao G, Macarios D (2012) Treatment satisfaction and persistence among postmenopausal women on osteoporosis medications: 12-month results from POSSIBLE US. Osteoporos Int 23:733741

40. Kendler DL, Macarios D, Lillestol MJ, Moffett A, Satram-Hoang S, Huang J, Kaur P, Tang ET, Wagman RB, Horne R (2014) Influence of patient perceptions and preferences for osteoporosis medication on adherence behavior in the Denosumab Adherence Preference Satisfaction study. Menopause 21:25-32 